\title{
Los of vas geskryf: die leksikograaf, die spelreëls en die taalwerklikheid
}

\author{
W.F. Botha, Buro van die Woordeboek van die Afrikaanse Taal
}

\begin{abstract}
Word Group and Complex: The Lexicographer, the Spelling Rules and the Language Reality. In the lexicon of Afrikaans there are lexical items that can occur as a word group and as a complex without a difference in meaning, e.g. rooi uryn (red wine) and rooiwyn. In some instances conflict exists between the spelling rules concerning this phenomenon and the language reality. The article deals with the treatment of the conflict by Afrikaans descriptive dictionaries. The lexicographic treatment of the conflict between spelling rules and language reality is determined by the type of dictionary involved. The inclusive dictionary is descriptive by nature and should give an honest and complete account of the language reality. The desk dictionary is prescriptive by nature and is concemed with the correct use of language as determined by, for instance, spelling rules. The 1991 edition of the Afrikaanse Woordelys en Spelreels narrowed the gap between spelling rules and language reality and simplified the task of the lexicographer considerably. Suggestions are made for alternative treatments and the improvement of the existing treatment of lexical items occurring as word groups and complexes.
\end{abstract}

Keywords: WORD GROUP AND COMPLEX, SPELLING RULES, LANGUAGE REALITY, LEXICOGRAPHER, INCLUSIVE DICTIONARIES, DESK DICTIONARIES, ALTERNATIVE TREATMENT

Opsomming: Los en vas geskrewe leksikale items is items wat in dieselfde volgorde, sonder die tussenkoms van ander leksikale elemente, en met eenderse betekenis in woordgroep- of kompositumvorm kan voorkom, bv. weet eens/weeteens. Tussen die spelreëls rondom hierdie verskynsel en die taalwerklikheid bestaan daar soms 'n botsing. Die leksikografiese hantering van botsings tussen die spelreëls en die taalwerklikheid word bepaal deur die tipe woordeboek wat ter sprake is. Die omvattende woordeboek met sy deskriptiewe karakter bepaal hom slegs by die weerspieëling van die taalwerklikheid terwyl die handwoordeboek (standaardwoordeboek) vanweë sy preskriptiewe karakter slegs korrekte taalgebruik, soos bv. deur die spelreëls bepaal, weergee. Met die verskyning van die 1991-uitgawe van die Afrikaanse Woordelys en Spelreßls het die spelreëls en die taalwerklikheid nader aan mekaar beweeg en die taak van die leksikograaf merkbaar vergemaklik. Voorstelle vir alternatiewe hanteringswyses en die verbetering van huidige hanteringswyses van los en vas geskrewe items in verklarende Afrikaanse woordeboeke word gemaak.

Sleutelwoorde: LOS EN VAS GESKREWE LEKSIKALE ITEMS, SPELREëLS, TAALWERKLIKHEID, LEKSIKOGRAAF, OMVATTENDE WOORDEBOEK, HANDWOORDEBOEK, ALTERNATIEWE HANTERINGSWYSES 


\section{Los en vas geskrewe leksikale items}

Met die verskyning van die nuwe Afrikaanse Woordelys en Spelreëls in 1991 het leksikale items wat los óf vas geskryf kan word opnuut onder die aandag gekom. Die doel van hierdie artikel is nie 'n bespreking van die reëls ten opsigte van los en vas skryf nie, maar wel die leksikografiese hantering van hierdie ortografiese verskynsel kenmerkend van die Afrikaanse spelling in verklarende Afrikaanse woordeboeke. Die artikel is gerig op 'n praktiese oplossing en is nie in die eerste plek op die teorie ingestel nie.

Los en vas geskrewe leksikale items is items wat in dieselfde volgorde, sonder die tussenkoms van ander leksikale items, en met eenderse betekenis in woordgroep- en kompositumvorm kan voorkom, bv. klavier speel / klavierspeel, reg denkend / regdenkend en weer eens / weereens.

2. Leksikografiese hantering van los en vas geskrewe leksikale items in verklarende Afrikaanse woordeboeke

\subsection{Handwoordeboeke}

Verklarende Afrikaanse handwoordeboeke weerspieël nie dikwels die moontlikheid dat 'n leksikale item los én vas geskryf kan word nie en het ook geen sisteem waarvolgens 'n los vorm gelemmatiseer kan word nie. Die frekwensie van die los vorm word selde aangedui.

Die Verklarende Handwoordeboek van die Afrikaanse Taal neem slegs twee gevalle op, nl.:

hoërskool. Ook hoër skool.

laerskool. Ook laer skool.

Die Nasionale Woordeboek neem die volgende gevalle op:

eweseer. (ewe seer)

eweso. (ewe so)

hoërskool. (ook hoër skool)

laerskool. (L.W. ook laer skool)

Die feit dat die los variasie in albei woordeboeke vet gedruk word, kan of dui op 'n poging om lemmastatus daaraan te verleen óf daarop dui dat dit gelykwaardig aan die kompositumvorm is wat gebruiksfrekwensie betref.

Deurdat die verklarende Afrikaanse handwoordeboeke in so min gevalle aandui dat 'n leksikale item ook los geskryf kan word, word daar eintlik vír die gebruiker 'n keuse gemaak ten opsigte van die skryfwyse van sekere leksikale items. Hierdie behandeling strook met die normatiewe karakter wat kenmer- 
kend is van handwoordeboeke (Gouws 1989: 70).

\subsection{Omvattende woordeboeke}

Omvattende woordeboeke het ' $n$ deskriptiewe karakter (Gouws 1989: 69) en het die getroue weerspieëling van ' $n$ taal se gebruik ten doel. Dit gaan dus nie om die beskrywing van korrekte taalgebruik nie, maar van werklike taalgebruik.

Die Woordeboek van die Afrikaanse Taal, die enigste omvattende Afrikaanse Woordeboek, het 'n vaste hanteringswyse vir los én vas geskrewe leksikale items. Die vas geskrewe vorm word as lemma opgeneem met vermelding van die los vorm en sy gebruiksfrekwensie. Die los vorm word dan onder ' $n$ bepaalde betekenisonderskeiding van die eerste komponent onder die sogenaamde tegniese uitdrukkings opgeneem.

Die definisie kom by die vorm wat volgens die beskikbare voorbeeldmateriaal die hoogste gebruiksfrekwensie het. Indien die vorme ewe gebruiklik is, word om praktiese redes, bv. vindbaarheid, voorkeur gegee aan die vas geskrewe variasie. Krombuig en die los variasie krom buig word bv. soos volg behandel in Deel VIII:

krombuig, w., kromgebuig; kromgebuig(de), kromgeboë. Meer dikw. krom buig, behalwe i.d. vorm v.d. attr. byv. gebruikte verl. dw. - sien onder KROM I 1a en b:

Die definisie verskyn by die los vorm krom buig wat onder die tegniese uitdrukkings van die lemma krom opgeneem is:

Krom buig (ook soms krombuig, veral i.d. vorm v.d. attr. byv. gebruikte verl. dw.; vgl. KROMBUIG, vbe.), buig sodat of totdat dit krom is of word: ...

In ander gevalle, bv. kleinmaak, word aangedui dat in sommige betekenisonderskeidings die los vorm meer frekwent is (meer dikw. klein maak) en in ander onderskeidings die vaste en los vorm ewe gebruiklik is (ook klein maak):

kleinmaak, w. ... 1. Meer dikw. los geskryf klein maak (vgl. KLEIN ${ }^{1}$ I, 1 c). In kleiner stukke verdeel: ...

2. a. Ook los geskryf klein maak (vgl. KLEINI I, 11 bii). Wissel vir kleingeld ...

3. Ook los geskryf klein maak (vgl. KLEIN ${ }^{1}$ I, 14 a). Klein, onbeduidend laat voel: ... 
Onder die onderskeie betekenisonderskeidings van klein word die los en vas vorme dan weer met mekaar in verband gebring met vermelding van die gebruiksfrekwensie.

\section{Spelreëls versus Taalwerklikheid: 'n Metaleksikografiese beskouing}

\subsection{Botsing tussen Spelreëls en Taalwerklikheid}

Dit is nie die bedoeling om hier kritiek uit te spreek teenoor die agste uitgawe van die Afrikaanse Woordelys en Spelreëls (voortaan die AWS) se uitsprake ten opsigte van los en vas nie. Dit gaan slegs om die leksikografiese hantering van die botsing tussen die spelreëls en die taalwerklikheid, en nie oor watter party "reg" of "verkeerd" is nie.

Tussen die spelreëls en die taalwerklikheid bestaan daar dikwels 'n skerp botsing. Tot met die verskyning van die agste uitgawe van die AWS in 1991 is slegs die los geskrewe vorm weer eens in Afrikaans erken. Die feitelike situasie was egter dat 'n aansienlike getal gebruikers van Afrikaans weereens geskryf het omdat hulle taalgevoel vir hulle gesê het dat weereens as 'n eenheid optree. Die leksikografiese hantering van botsings tussen die spelreëls en die taalwerklikheid word bepaal deur die tipe woordeboek wat ter sprake is.

Vervolgens word daar 'n kort oorsig gegee van die spelreëls, gevolg deur 'n besinning oor die verskillende tipes woordeboeke se hantering van bogenoemde botsing en van los én vas geskrewe items in die algemeen.

\subsection{Die 1991-spelreëls}

'n Kenmerk van die nuwe reëls ten opsigte van los én vas geskrewe leksikale items is dat dit grootliks op die taalwerklikheid gebaseer is. Die moontlikheid van ' $n$ botsing tussen die taalwerklikheid en die spelreëls is dus vir die huidige afgeweer en die omvattende woordeboek kan aanvullend by die AWS optree deurdat dit die gebruiksfrekwensie van die los en vas vorme aandui.

Indien ek afdeling 15 (pp. 65 tot 80 ) van die spelreëls korrek interpreteer, onderskei die 1991-AWS, behalwe telwoorde en verbindings met eiename, die volgende tipes verbindings wat los óf vas geskryf kan word:

(1) verbindings van adjektiewe en naamwoorde soos die volgende gevalle: kort golf/kortgolf, rooi wyn/rooiwyn, lang broek/langbroek. Die los en vas skryf het geen verandering in betekenis tot gevolg nie. Dit gaan dus hier bloot om ortografiese verskille, anders as in gevalle soos geel perske/geelperske en groot mens/grootmens waar daar ook betekenisverskille ter sprake is. 
(2) verbindings waarin die kernwoord 'n adjektief is soos die volgende gevalle:

(2.1) keurig versorgde/keurigversorgde werk, volmaak beheerde/volmaakbeheerde handrughou, plaaslik vervaardigde/ plaaslikvervaardigde onderdele;

(2.2) medies geskik/mediesgeskik, statisties beduidend/statistiesbeduidend, serebraal verlam/serebraalverlam;

(2.3) tuis gemaakte/tuisgemaakte, snel groeiende/snelgroeiende, goed gesinde/goedgesinde;

(3) vaste werkwoordelike verbindings soos die volgende gevalle: kennis maak/kennismaak, perd ry/perdry, swaar kry/swaarkry, mis slaan/misslaan, klein maak/kleinmaak. Hierdie tipe werkwoord staan ook bekend as 'n deeltjiewerkwoord en het die kenmerk dat die deeltjie en die werkwoordelike komponent omstelbaar is, bv. misslaan en slaan mis;

(4) bywoordelike uitdrukkings met eens word vas geskryf: ineens, meteens, nogeens, opeens, weereens, maar ter wille van die tradisie word ook nog eens en weer eens erken;

(5) verbindings met hier en daar waar dit nie altyd moontlik is om te onderskei of hulle as bywoorde of voornaamwoorde optree nie, soos die volgende gevalle: hier benewens/hierbenewens, hier bo/hierbo en daar agter/daaragter;

(6) verbindings wat bestaan uit voornaamwoorde en die versterkende element self soos die volgende gevalle: $e k$ self/ekself, my self/myself en $u$ self/uself.

Die volgende tipes verbindings word nie pertinent onder die spelreëls vermeld nie, maar word wel in die woordelys aangegee:

(7) verbindings wat bestaan uit ' $n$ selfstandige naamwoord en 'n adjektief, soos bv. kop omlaag/kopomlaag en kop onderstebo/koponderstebo;

(8) enkele bywoordelike verbindings met ewe, soos bv. ewe seer/eweseer en ewe so/eweso;

(9) historiese verbindings van adjektiewe en naamwoorde soos ouder gewoonte/oudergewoonte; 
(10) historiese voorsetselverbindings (voorsetselgroepe én groepsetsels) wat los, vas of gedeeltelik vas geskryf kan word: in der minne/inderminne, in der haas/inderhaas, op laas/oplaas, van pas/vanpas, ter wille van/terwille van, op heter daad/op heterdaad;

(11) vaste werkwoordelike verbindings wat los en gedeeltelik vas geskryf kan word: te berde bring/teberde bring, te kere gaan/tekere gaan.

\subsection{Omvattende woordeboeke}

Spelreëls, of 'n verandering in die spelreëls, raak in werklikheid nie die omvattende woordeboek nie, omdat dit die feitelike situasie, die taalwerklikheid, en nie die teorie nie, weerspieël. Dit geld dan ook die los en vas skryf van leksikale items.

Indien 'n omvattende woordeboek op enige gegewe tydstip, bv. vóór die verskyning van die agste uitgawe van die AWS, op grond van sy dataversameling sou oordeel dat weereens en weer eens ewe gebruiklik is, behoort hy dit te weerspieël in sy hanteringswyse:

weereens bw. Ook los geskryf, weer eens. Nog 'n keer: ...

Hierdie behandeling sal, ongeag die spelreëls, geldig wees totdat die taalwerklikheid verander. Indien weereens bv. in die toekoms die skryfwyse word met die hoogste gebruiksfrekwensie, sou die inskrywing soos volg kon lyk:

weereens bw. Ook soms los geskryf, weer eens. Nog 'n keer: ...

Voor 1991 is luuks nie as 'n leksikale item erken nie en het dit in geen Afrikaanse handwoordeboek, woordelys of vertalende woordeboek verskyn nie. Slegs die selfstandige vorm luukse en die byvoeglike vorm luuksueus het amptelike erkenning geniet. Reëlgebonde taalgebruikers het meestal die kompositumvorms luukse-artikel, luuksemotor, ens. gebruik terwyl adjektiefstukke soos luuksueuse artikel, luuksueuse motor, ens. 'n heelwat laer gebruiksfrekwensie gehad het. Spontane taalgebruikers het voorkeur verleen aan luukse artikel, luukse motor, ens. Of al dié gebruikers luukse as 'n byvoeglike naamwoord beskou het, en of sommige luukse artikel, luukse motor, ens. as 'n losgeskrewe variasie van luukse-artikel, luuksemotor, ens. bedoel het, is moeilik te bepaal. Die totale werklikheid moet egter deur die omvattende woordeboek weerspieël word en die leksikografiese hantering behoort voor 1991 en tans dieselfde te wees. 'n Moontlike hanteringswyse is:

luuks b.nw., luukse; luukser, luuksste. Wat van weelde en prag getuig; sin. luuksueus (minder gebruiklik): Luukse artikel, goedere, hotel, uitgawe. 
luukse s.nw., luukses. Enigiets wat luuks en dikw, onbekombaar is; sin. luuksheid; luuksigheid (geselstaal; minder gebruiklik): Iets as 'n luukse beskou. In luukse leef. Jou die luukse veroorloof.

Onverklaarde samestellings:

luukse-artikel s.nw., luuksebus s.nw., luuksehotel s.nw., luukse-uitgawe s.nw., luuksewoonstel s.nw.

luuksueus b.nw., luuksueuse; luuksueuser, luuksueusste (minder gebruiklik). Luuks: Luuksueuse bus, motor ...

Die spelreëls en die taalwerklikheid het wel nader aan mekaar beweeg ten opsigte van los en vas geskrewe leksikale items, maar in sommige gevalle is daar 'n tydelike of potensieel permanente botsing geskep. In die meeste gevalle is dié botsing opgelos deur volkome erkenning aan die taalwerklikheid te gee. Só is erkenning gegee aan weer eens én weereens terwyl slegs weer eens in die ou bedeling erken is. Soms is vas egter na los verander, liewers as om aan beide vorme erkenning te gee. Privaat sekretaris moet voortaan los geskryf word terwyl die ou voorskrif privaatsekretaris (of private sekretaris) was. So ook wit man, bruin vrou, ens. teenoor witman, bruinvrou, ens. van die verlede. Dit sal egter geruime tyd duur, indien ooit, voordat alle taalgebruikers privaat sekretaris en bruin vrou skryf. Hoewel die nuwe skryfwyse op 'n logiese grondslag myns insiens regverdigbaar is, sal slegs die tyd leer of die botsing sal voortbestaan of verdwyn.

Met elke verandering in die spelreëls ontstaan daar outomaties ' $n$ botsing met die taalgebruik van die verlede. Die omvattende woordeboek is gerig op die hede én die verlede en moet hierdie verwikkelde taalwerklikheid weerspieël. Hiervoor word ' $n$ uiters verteenwoordigende dataversameling vereis ten einde ' $n$ noukeurige aanduiding van die gebruiksfrekwensie moontlik te maak. Indien die data bv. oor die tydperk 1900 - 1992 versamel is, mag daar in totaal meer opgawes van die kompositumvorm privaatsekretaris (die korrekte spelwyse volgens die 1964-reëls) as die los vorm wees. Die data wat oor die laaste twee jaar, 1991 - 1992, versamel is, mag moontlik meer opgawes van die los vorm privaat sekretaris (die korrekte spelwyse volgens die 1991-reëls) bevat. Dit sou die leksikograaf in staat stel om 'n presiese weergawe van die gebruiksfrekwensie van die verskillende vorme te gee deur middel van 'n inskrywing soos die volgende:

privaatsekretaris s.nw. Tans meer dikw. privaat sekretaris. Sekretaris wat 


\subsubsection{Die los vorm as multileksikale lemma}

Idealiter behoort die los geskrewe variasie as multileksikale lemma opgeneem te word indien dit 'n hoër gebruiksfrekwensie as die kompositumvorm het. Die kompositumvorm en sy gebruiksfrekwensie kan dan daarby vermeld word. In die metaleksikografie is reeds wyses aangedui waarop meerwoordige leksikale items met erkenning van hul leksikale-itemstatus gelemmatiseer kan word (vgl. Gouws 1990 en Botha 1991).

Vir die leksikograaf is die alfabetiese lemmatisering van meerwoordige leksikale-items volgens die aanvangskomponent die logiese aanbiedingswyse, maar dit lewer ernstige praktiese probleme op (Botha 1991). Die vernaamste van hierdie probleme is die opeenhoping van multileksikale lemmas wat met lidwoorde en sekere voorsetsels en voomaamwoorde begin. Daar is byvoorbeeld letterlik honderde uitdrukkings wat met die voorsetsels in, met en op begin, om nie eers te praat van die talle wat die as aanvangskomponent het nie. Dit kan baie frustrerende soektogte vir die woordeboekgebruiker tot gevolg hê.

'n Metode van gemerkte lemmatisering waarvolgens multileksikale lemmas volgens bepaalde kemkomponente (wat lidwoorde, voorsetsels en voornaamwoorde uitsluit) gealfabetiseer word, word deur Gouws (1990) en Botha (1991) voorgestel. Hiervolgens sou die los en vas geskrewe leksikale item in der minne/inderminne soos volg gelemmatiseer kon word indien in der minne die hoogste gebruiksfrekwensie het:

minne: in der minne Ook soms inderminne. Op vreedsame of vriendelike wyse:

Dit is egter te betwyfel of dit vir die woordeboekgebruiker enige voordele inhou indien die los geskrewe variasie as multileksikale lemma opgeneem word. Die woordeboekgebruiker is oorwegend woord-georiënteerd en sal outomaties na die kompositumvorm soek. Indien hy van mening is dat die item los geskryf word, sal hy dit in elk geval nie in 'n woordeboek naslaan nie, omdat die woordeboek "woorde" opneem en die los vorm nie vir hom iets is wat nageslaan kan word nie. Die meer "gevorderde" gebruiker sal besef dat indien die item los en vas geskryf kan word, die los vorm by die kompositum vermeld sal word.

Dit is nie nodig om aparte inskrywings vir beide vorme te maak nie omdat dit hier gaan om een leksikale item wat ortografies op twee wyses weergegee kan word. Daar is dus nie regverdiging vir die WAT (Deel I tot VIII) se aangawe van die los variasie onder die sg. tegniese uitdrukkings nie. 


\subsubsection{Alternatiewe hanteringswyses van die los geskrewe vorm}

\subsubsection{Deel van die voorbeeldmateriaal}

In die geval van 'n deursigtige samestelling met 'n los vorm, bv, pasgebore/pas gebore, kan die vaste vorm as onverklaarde samestelling opgeneem word en die los vorm as deel van die voorbeeldmateriaal by die leksikale lemmas, bv. pas en gebore.

\subsubsection{Vermelding in 'n opmerking of streeplemma}

Indien daar tog ' $n$ behoefte bestaan om die los- en vasgeskrewenheid toe te lig, kan dit op twee maniere gedoen word: deur die gebruik van 'n opmerking by 'n leksikale lemma wanneer daar nie baie voorbeelde met bv. pas as eerste komponent is nie, en deur 'n streeplemma (koppeltekenlemma) wanneer daar baie voorbeelde met ' $n$ bepaalde eerste komponent, bv. dig, is:

pas bw....

OPM: Pas verbind in kompositum- of woordgroepvorm met verlededeelwoordvorme, bv.: pasgetroud/pas getroud, pasgebore/pas gebore.

dig- Aanvangskomponent van verskeie leksikale items wat in kompositum- of woordgroepvorm voorkom, bv.: digbevolk/dig bevolk, digbegroei/dig begroei.

Tipes los en vas geskrewe leksikale items wat, indien hulle nie verklaring verdien nie, met 'n OPM. of 'n streeplemma behandel kan word, is veral:

(1) dig begroei/digbegroei, bes bedoel/besbedoel, hoër liggend/hoërliggend, pas gebore/pasgebore, ens.;

(2) ineen stort/ineenstort, plat drik/platdruk, bekend stel/bekendstel, ens.;

(3) raak skoot/raakskoot, baie keer/baiekeer, mat verf/matverf, ens.;

(4) waar aan/waaraan, hier agter/hieragter, daar benewens/daarbenewens, ens.;

(5) borg staan/borgstaan, belang stel/belangstel, korrel zat/korrelvat, ens. 


\subsection{Handwoordeboeke}

Omdat handwoordeboeke 'n voorskriftelike karakter het, sal hulle 'n noukeurige weergawe van die AWS se voorkeure ten opsigte van los en vas geskrewe leksikale items moet gee. Handwoordeboeke loop dus die gevaar om verouderd te raak met elke wysiging in die spelreëls.

Die jongste uitgawes van die Nasionale Woordeboek en die Handwoordeboek van die Afrikaanse Taal bevat slegs die vier leksikale items wat in die woordelys van die 1964-AWS as los en vasgeskrewe aangedui word (ewe seer/eweseer, ewe soleweso, hoër skool/hoërskool, laer skool/laerskool). Die 1964-AWS het in al die ander gevalle van los of vas geskrewe items slegs die los of die vas geskrewe variasie in die woordelys opgeneem. Daardeur word 'n bepaalde voorkeur uitgespreek en 'n handwoordeboek moet noodwendig daarop reageer.

In die woordelys van die 1991-AWS word die meerderheid van die gevalle in beide vorme opgeneem wat in die spelreëlafdeling as los en vas geskrewe aangedui is. Hierbenewens word ook nog talle gevalle aangegee wat nie pertinent in die spelreëls vermeld is nie ( $\mathrm{vgl} .3 .2(7)$ - (11)).

Voorbeelde van leksikale items wat volgens die spelreëls los of vas geskryf kan word, maar in die woordelys slegs in kompositumvorm opgeneem is, is die volgende: kortgolf, langbroek, goedgesind, goedgelowig, snelgroeiend, regdenkend, nogeens. Voorbeelde wat volgens die spelreëls los of vas geskryf kan word, maar in die woordelys slegs in woordgroepvorm opgeneem is, is: root wyn, sagte vrugte, keurig versorg, plaaslik vervaardig, goed gemanierd, vinnig groeiend, te goeder trou. Handwoordeboekmakers moet egter daarvan kennis neem dat die Taalkommissie van voorneme is om in 'n 1996-uitgawe regstellings te maak waar sekere vorme in die spelreëls as gelykwaardig geag is, maar net een vorm in die woordelys opgeneem is (Die Burger, 21 Mei 1992: 18).

Handwoordeboeke behoort dus in die toekoms, in die lig van die 1991-woordelys en veral die verklaarde voorneme van die Taalkommissie om nog meer keusevorme in 1996 op te neem, 'n aansienlik groter getal los óf vas geskrewe leksikale items te lemmatiseer.

Die Afrikaanse handwoordeboeke moet op 'n konsekwente hanteringswyse besluit en ook ' $n$ aanduiding gee van die frekwensie van die verskillende vorme. ' $n$ Hibridiese aanbiedingswyse soos in die Nasionale Woordeboek is nie aanvaarbaar nie:

eweseer. (ewe seer)

eweso. (ewe so)

hoërskool. (ook hoër skool)

laerskool. (L.W. ook laer skool)

Handwoordeboeke kan ook oorweging daaraan skenk om die los geskrewe variasies as multileksikale lemmas op te neem en om inligting oor los- en vas 
geskrewenheid te verskaf deur middel van 'n opmerking of streeplemma (vgl. 3.3.2 hierbo).

\section{Slotwoord}

Met die verskyning van die agste uitgawe van die AWS het die spelreëls en die taalwerklikheid nader aan mekaar beweeg en die werk van die leksikograaf merkbaar vergemaklik. Daar is egter nog onontginde moontlikhede vir die hantering van leksikale items wat los en vas geskrewe variasies het en die hoop word uitgespreek dat die voorstelle in hierdie artikel die praktiserende leksikograaf tot nut mag wees.

\section{Verwysings}

\section{Woordeboeke en woordelyste}

De Villiers, M. e.a. 19856. Nasionale Woordeboek. Kaapstad: Tafelberg.

Odendal, F.F. 19792. Verklarende Handwoordeboek oan die Afrikaanse Taal. Doomfontein: Perskor.

Schoonees, P.C.JF.J. Snijman/D.C. Hauptfleisch (Reds.). 1950-1991. Woordeboek zan die Afrikaanse Taal. Pretoria: Staatsdrukker/Stellenbosch: Buro van die WAT.

Taalkommissie van die Suid-Afrikaanse Akademie vir Wetenskap en Kuns. 19918. Afrikaanse Woordelys en Spelreéls. Kaapstad: Tafelberg.

\section{Ander bronne}

Botha, W.F. 1991. Die lemmatisering van uitdrukkings in verklarende Afrikaanse woordeboeke. Harteveld, P. (Red.). 1991: $20-36$.

Die Burger, Kaapstad, 21 Mei 1992: 18.

Gouws, R.H. 1989. Leksikografie. Kaapstad: Academica.

Gouws, R.H. 1990. Vaste uitdrukkings as multileksikale lemmas in verklarende Afrikaanse woordeboeke. Tydskrif oir Geesteswetenskappe 30(4): 265-283.

Harteveld, P. (Red.). 1991. Lexikos. AFRILEX-reeks 1:1991. Stellenbosch: Buro van die WAT. 